We acknowledge the excellent technical help of R A Gray and Mrs C Menzies. This work was supported by the Muscular Dystrophy Group of Great Britain. The fluorescence activated cell sorter model IV was provided by the Cancer Research Campaign.

${ }^{1}$ Behan WMH, Behan PO. A comparison between human polymyositis and the putative animal model, experimental allergic myositis. In: Rose FC, Behan PO, eds. Animal models of neurological disease. London: Pitman Medical, 1980:72-89.

${ }^{2}$ Weiner HL, Hauser SL. Neuroimmunology 1: Immunoregulation in neurological disease. Ann Neurol 1982;11:437-49.

${ }^{3}$ Reinherz EL, Kung PC, Goldstein G, Schlossman SF. A monoclonal antibody with selective reactivity with functionally mature human thymocytes and all peripheral human $T$ cells. 7 Immunol $1979 ; 123$ : 1312-7.

4 Ledbetter JA, Rouse RV, Micklem HS, Herzenberg LA. T cell subsets defined by expression of Lyt-1,2,3 and Thy-1 antigens. $\mathcal{F}$ Exp Med 1980; 152:280-95.

5 Bresnan MJ, Hauser SL, Weiner HL, Reinherz E, Borel Y, Bhan A Characterization of $\mathrm{T}$-cell subsets in peripheral blood and muscle in childhood dermatomyositis [Abstract]. Ann Neurol 1981;10:283.

(Accepted 7 April 1983)

\section{Glasgow University, Glasgow}

WILHELMINA M H BEHAN, MB, FRCPATH, senior lecturer in pathology P O BEHAN, MD, FRCP, reader in neurology

Edinburgh University, Edinburgh

H S MICKLEM, DPHIL, reader in zoology

Glasgow Royal Infirmary, Glasgow

W F DURWARD, MB, FRCPGLAS, consultant neurologist

Correspondence to: Dr P O Behan, Institute of Neurological Sciences, Southern General Hospital, Glasgow G51 4TF.

\section{Cardiac arrhythmias during high spinal surgery}

Sudden unexpected cardiac arrest during surgery on the upper thoracic spine has been reported, and there has been speculation about the role of sympathetic stimulation in precipitating ventricular fibrillation. ${ }^{1}$ I report a case in which cardiac arrhythmias were observed related to surgical stimulation during total laminectomy at the level of the first and second thoracic vertebras for excision of an intradural neurofibroma.

\section{Case report}

The patient, a previously fit 62 year old woman, gave a two year history of increasing weakness of the left leg. There was radiological evidence of an intradural mass at the level of the second thoracic vertebra. As a result of a sudden deterioration in her neurological state immediate operation was decided on. She had received two previous general anaesthetics, the most recent being 15 months previously for a stapedectomy. There had been no problems during anaesthesia. Systematic inquiry elicited no symptoms related to the cardiovascular or respiratory system. She took no medication and had no known allergies. Pulse rate was 60 beats $/$ min with a regular rhythm and blood pressure $130 / 80 \mathrm{~mm} \mathrm{Hg}$. Physical examination showed no abnormalities other than that in the central nervous system.

Anaesthesia was induced with sodium thiopentone $300 \mathrm{mg}$ and suxamethonium chloride $75 \mathrm{mg}$. The trachea was then intubated with an $8.5 \mathrm{~mm}$ armoured latex endotracheal tube. Air entry to both lungs was checked by auscultation. Ventilation was maintained with a Cape Waine mark III anaesthetic ventilator using $30 \%$ oxygen and $70 \%$ nitrous oxide. Ventilation was adjusted to produce an end tidal carbon dioxide concentration of 3.0-3.5\% with an inflation rate of 10 breaths $/ \mathrm{min}$. Expired tidal volume, measured with a Wright respirometer, was $650 \mathrm{ml}$. The inflation pressure was $20 \mathrm{~cm}$ water.

She was placed in the prone position with supports under the chest and pelvis. Anaesthesia was maintained with papaveretum given in divided doses to a total of $15 \mathrm{mg}$ and halothane $0.5 \%$ delivered via a Fluotec mark III vapouriser. Muscle relaxation was maintained with pancuronium bromide $6 \mathrm{mg}$. Systolic blood pressure was measured with a sphygmomanometer cuff around the upper arm; throughout anaesthesia it remained within the range $100-120 \mathrm{~mm} \mathrm{Hg}$. An intravenous infusion was established, and a total of $900 \mathrm{ml}$ crystalloid plus one unit of whole blood was infused during surgery and the immediate postoperative period.

At the start of surgery an electrocardiogram showed sinus rhythm with a rate of $80-90$ beats $/ \mathrm{min}$. As the laminas were removed and dura exposed multifocal ventricular ectopics appeared with a frequency varying between one in six and one in 20 normal beats. The frequency of these ectopic beats was directly related to surgical stimulation, falling when surgery was stopped and immediately increasing when surgical stimulation was resumed. During this period the blood pressure remained stable with no evidence of any adverse haemodynamic effects. Neither additional analgesia in the form of further incremental doses of papaveretum nor withdrawal of the halothane appeared to affect the nature or frequency of the arrhythmias. The ectopic beats continued at a lower frequency for the next 24 hours. A 12 lead electrocardiogram obtained six days postoperatively showed normal sinus rhythm with no ectopic beats and no evidence of myocardial ischaemia. There were no cardiac enzyme changes.

\section{Comment}

It has been shown experimentally in primates that acute compression of the spinal cord in the mid-thoracic region can produce cardiac arrhythmias. ${ }^{2}$ These effects are mediated via the sympathetic and parasympathetic nervous systems and may be abolished by adrenergic and cholinergic blockade. As cardiac arrest may occur during high thoracic laminectomy this may be the precipitating mechanism. The above case report emphasises the necessity of continuous electrocardiographic monitoring during the procedure, and the results of animal experiments suggest that prophylactic cholinergic or adrenergic blockade, or both, may be appropriate.

${ }^{1}$ Marshall MM. Neuroanaesthesia. London: Edward Arnold, 1979:58. (Current Topics in Anaesthesia No 3.)

${ }^{2}$ Evans DE, Kobrine AI, Rizzoli HV. Cardiac arrhythmias accompanying acute compression of the spinal cord. 7 Neurosurg 1980;52:52-9.

(Accepted 15 April 1983)

Department of Anaesthesia, Newcastle General Hospital, Newcastle upon Tyne NE4 6BE

P R RAYNER, MB, FFARCS, senior registrar

Correspondence to: Dr P R Rayner, Department of Anaesthesia, Royal Victoria Infirmary, Newcastle upon Tyne.

MEDICINES HOT IN THE FIRST DEGREE-Those are said to be hot in the first degree, which induce a moderate and natural heat to the body, and to the parts thereof; either cold by nature, or cooled by accident, by which natural heat is cherished when weak, or restored when wanting. The first effect then of medicines hot in the first degree is, by their sweat and temperate heat to reduce the body to its natural heat, as the fire doth the external parts in cold weather, unless the affliction of cold be so great that such mild medicines will not serve the turn. The second effect is, the mitigation of pain arising from such a distemper, and indeed this effect hath other medicines, some that are cold, and some that are hotter than the first degree, they being rationally applied to the distemper. These medicines the Greeks call Anodyna, and shall be spoken of in their proper places. In this place let it suffice that medicines hot in the first degree, make the offending humours thin, and expel them by sweat, or insensible transpiration, and these of all others are most congruous or agreeable to the body of man, for there is no such equal temperature of heat and cold in a sound man, but heat exceeds, for we live by heat and moisture, and not by cold. Medicines then which are hot in the first degree, are such as just correspond to the natural heat of our bodies; such as are hotter or colder, are more subject to do mischief, being administered by an unskilful hand, than these are, because of their contrariety to nature; whereas these are grateful to the body by their moderate heat. Thirdly, These take away weariness, and help fevers, being outwardly applied, because they open the pores of the skin, and by their gentle heat prepare the humours, and take away those fuliginous vapours that are caused by fevers. Yet may discommodities arise by heedless giving even of these, which I would have young students in physic be very careful in, lest they do more mischief than they are aware of, viz It is possible by too much use of them, to consume not only what is inimical in the body, but also the substance itself, and the strength of the spirits, whence comes faintings, and sometimes death: besides, by applying them to the parts of the body they are not appropriated to, or by not heeding well the complexion of the patient, or the natural temper of the part of the body afflicted, for the heart is hot, but the brain temperate. Lastly, Medicines hot in the first degree, cherish heat in the internal parts, help concoction, breed good blood, and keep it good in temper, being bred. (Nicholas Culpeper (1616-54) The Complete Herbal, 1850.) 